IFN Working Paper No. 843, 2010

\title{
Exposure-Based Cash-Flow-at-Risk for Value-Creating Risk Management under Macroeconomic Uncertainty
}

Niclas Andrén, Håkan Jankensgård and Lars Oxelheim 


\title{
EXPOSURE-BASED CASH-FLOW-AT-RISK FOR VALUE- CREATING RISK MANAGEMENT UNDER MACROECONOMIC UNCERTAINTY
}

\author{
Niclas Andrén, Department of Business Administration, Lund University, \\ Sweden
}

Håkan Jankensgård, Department of Business Administration, Lund University, Sweden

Lars Oxelheim, Lund Institute of Economic Research, Lund University and the Research Institute of Industrial Economics, Stockholm, Sweden.

\begin{abstract}
:
A strategically minded $\mathrm{CFO}$ will realize that strategic corporate risk management is about finding the right balance between risk prevention and proactive value generation. Efficient risk and performance management requires adequate assessment of risk and risk exposures on the one hand and performance on the other. Properly designed, a risk measure should provide information on to what extend the firm's performance is at risk, what is causing that risk, the relative importance of non-value-adding and value-adding risk, and the possibilities to use risk management to reduce total risk. In this chapter, we present an approach - exposure-based cash-flow-at-risk - to calculating a firm's downside risk conditional on the firm's exposure to non-value-adding macroeconomic and market risk and to analyzing corporate performance adjusted for the impact of non-value-adding risk.
\end{abstract}

Key words: cash-flow-at risk, value at risk, risk management, value creation, total risk

JEL: E32, G32, G33, G34, M16, M21

Forthcoming in Fabich, M., L. Firnkorn, U. Hommel and E. Schellenberg (eds.), The Strategic $\mathrm{CFO}$ - Creating Value in a Dynamic Market Environment. Heidelberg: Springer Verlag.

Financial support from the NASDAQ OMX Nordic Foundation for Lars Oxelheim is gratefully acknowledged. 


\section{EXPOSURE-BASED CASH-FLOW-AT-RISK FOR VALUE-CREATING RISK MANAGEMENT UNDER MACROECONOMIC UNCERTAINTY}

\section{Introduction}

A strategically minded CFO will realize that strategic corporate risk management is about finding the right balance between risk prevention and proactive value generation. In short, risk management and performance management are two sides of the same coin. As an example, take the eruption of the recent financial crisis in mid-September 2008. In just three days, following the bankruptcy of Lehman Brothers, the fire sale of Merrill Lynch, and the nationalization of American Insurance Group, the US federal-funds markets came to a standstill and market liquidity for risky credits dried up. Improper balance between risk and performance management exacerbated the crisis. Inefficient risk management failed to prevent the spillover of the crisis across the banking sector, and the ensuing breaks put on risk taking forced credit markets to a complete halt.

Risk prevention is value adding if it is used to exploit market inefficiencies faced by the firm, for example, in the form of convex marginal financial distress costs (Mayers and Smith, 1982; Smith and Stulz, 1985) or, more generally, convex costs of raising external financing (Froot, Scharstein, and Stein, 1993, 1994). It will also enhance corporate performance if reducing exposures to non-value-adding, or passive, risks will improve the company's ability to carry what Robert C Merton calls value-adding risks (Merton, 2005; also see Schrand and Unal, 1998; Stulz, 1996).

Risk management is often delegated to a specialist function in the corporate hierarchy, typically the treasury. This is unfortunate, since the result will be that risk management is focused on tactics of risk control, unrelated to the core managerial activity of creating and sustaining competitive advantage. Derivatives markets allow the strategic CFO to engineer 
corporate risks so that virtually the only risks remaining are value-adding risks. Value-adding risks are risks generated by activities where the firm has a comparative advantage in bearing risk. A case in point is commercial banking (see Merton, 2005, for a more extensive discussion). Commercial banks take on two primary classes of risk. The backbone of their earnings potential is their ability to service customers, by investing in risky ventures such as opening offices, designing product offerings, lending money, etc. If managed correctly, such risk taking should generate residual earnings in excess of the cost of capital, implying that these risks are value-adding for a commercial bank that holds a competitive advantage in relationship management. The second class of risk is interest-rate risk. Large components of a commercial bank's financing are short term, not least interest paid on deposits. Lending is instead often at fixed interest rates. Spreads between lending and deposit rates are often tight, and if interest-rate risk is managed sub-optimally increases money market rates could turn out to be very costly. Interest-rate risk is a risk where most individual banks hold no comparative advantage in being exposed and remaining exposed accordingly does not produce positive net present value. Active interest-rate risk management allows banks to increase their lending activities, thereby leveraging their advantages in relationship management.

As financial institutions have long recognized, it is the lower tail of the cash flow or value distribution that has costly consequences in the form of financial distress or inability to invest in value-adding risk taking (Stulz, 1996). This realization motivates the importance of value-at-risk $(\mathrm{VaR})$ as a measure of risk taking in the financial sector, and it motivates why non-financial firms should stand to benefit from abandoning traditional volatility-based measures of risk, not least standard deviation, for internal risk management purposes in favor of measures of downside risk, such as cash-flow-at-risk (CFaR). Downside risk measures have the added advantage of being more consistent with how risk is actually perceived by corporate managers and investors, not least creditors (Libby and Fishburn, 1977; Tversky and Kahneman, 1979; Miller and Leiblein, 1996).

Efficient risk and performance management requires adequate assessment of risk and risk exposures on the one hand and performance on the other. Properly designed, a risk measure should provide information on to what extend the firm's performance is at risk, what is causing that risk, the relative importance of non-value-adding and value-adding risk, and the possibilities to use risk management to reduce total risk. In this chapter, we present an approach - exposure-based cash-flow-at-risk - to calculating a firm's downside risk 
conditional on the firm's exposure to non-value-adding macroeconomic and market risk and to analyze corporate performance adjusted for the impact of non-value-adding risk. Risk management is aimed at controlling the riskiness of corporate performance. The primary way to achieve this is to reduce corporate exposure to risk, not least the firm's exposure to macroeconomic and market risks, such as exchange-rate, interest-rate, and commodity-price risks. A measure of risk exposure tells to what extent corporate performance is influenced by unexpected changes in a risk factor, such as an exchange rate. Given this information, the exposure can be mitigated by, for example, entering into an offsetting hedge position. What the exposure measure does not do, however, is to tell the riskiness of the corporate performance due to the exposure, that is, the conditional risk.

How does it work? Exposure-based CFaR involves estimating a set of exposure coefficients that provide information about how changes in non-value-adding macroeconomic and market variables can be expected to influence the company's cash flow. These risk exposures can then be used to calculate $\mathrm{CFaR}$. The exposure model provides a set of exposure coefficients that are capable of explaining the variability in cash flow as a function of various risks; and for this reason, it can also be used to predict how a derivatives position or change in financial structure would change the company's risk profile. At the same time, our method also provides information about that part of the firm's cash flow variability that is not attributable to macroeconomic and market risks, but rather value-adding risk.

The rest of the chapter will take you through how to calculate exposure-based CFaR and how to extract information from the risk measure. We begin with an overview of strategic risk management and the usefulness of exposure-based CFaR. Drawing upon a case by Andrén, Jankensgård, and Oxelheim (20059 we demonstrate the application of exposurebased CFaR to Norsk Hydro, a Norwegian industrial company.

\section{Assessing cash flow at risk}

VaR was developed out of a desire to know the aggregate market risk of all trading desks across a financial institution. It targets the total risk of any portfolio or financial institution, and makes the aggregate risk of portfolios or companies directly comparable. It has received a fair amount of criticism (see, for example, Culp, Miller, and Neves, 1998), but it upholds its popularity with practitioners, academics, and policy makers. Not least, it has 
been adopted under the Basel II agreement as a standard method to determine the amount of regulatory capital that banks must hold. VaR has several advantageous features as a risk measure. It focuses on extreme losses, it aggregates different risks into a single number, and it is easy to both calculate and interpret, making it easy to communicate and base decisions on. $\mathrm{VaR}$ is essentially an extension of the classical probability of ruin (or probability of bankruptcy) concept, which has a long history in the reinsurance (Borch, 1967) and creditrisk-management (Altman, 1968; Scott, 1981; Altman and Saunders, 1998) literatures. However, instead of estimating the probability of ruin, a target probability is pre-specified $(0.1 \%$ and $1 \%$ are common probabilities in financial contexts) and $\mathrm{VaR}$ measures the maximum portfolio or company value that could be lost at this confidence level (99.9\% or $99 \%$ in the prior examples) over a specific time horizon.

VaR is clearly inappropriate for firms that, unlike financial firms, are not concerned with the value of stocks of assets and liabilities. If applied to a non-financial firm's portfolio of assets and liabilities VaR will capture only a small part of the company's overall exposure, since it ignores the risk of the company's underlying commercial cash flows. The at-Risk framework is still relevant in a non-financial context, however. In a non-financial company concerned with avoiding financial distress or avoiding liquidity shortfalls the relevant number is expressed in terms of cash flow rather than value. This brings us to $\mathrm{CFaR}$, which represents a transfer of the at-Risk framework to a setting where cash flow is the targeted variable. Whereas VaR measures the maximum amount of total value a firm can be expected to lose under most foreseeable conditions over a specific time horizon, $\mathrm{CFaR}$ measures the maximum shortfall of cash the firm is willing to tolerate.

$\mathrm{CFaR}$ is calculated in the same way as $\mathrm{VaR}$, but on cash flow rather than value. The calculation requires a forecast of the probability distribution for future levels of cash flow. The key difficulty is generating such a distribution. The easiest approach is to assume that cash flow is normally distributed. Knowing the mean and variance of this distribution, it is straightforward to calculate $\mathrm{CFaR}$ as the cash flow loss relative the mean corresponding to some pre-defined probability level in the left tail of the distribution. RiskMetrics, the first firm to develop $\mathrm{CFaR}$ for commercial purposes, relies on a pro forma approach for generating the cash flow distribution (RiskMetrics, 1999). In a pro forma approach the aim is to forecast each building block in a cash flow calculation rather than the cash flow directly. RiskMetrics uses production volumes, revenues and costs in local currency, and exchange rates as basic 
building blocks. By random sampling from a variance-covariance matrix for the building blocks in the cash flow calculation, a distribution of pro forma cash flows can be generated and $\mathrm{CFaR}$ calculated. The pro forma approach can easily be extended in various ways, for example, horizontally by estimating $\mathrm{CFaR}$ for individual building blocks or various cash flow concepts, or vertically by estimating $\mathrm{CFaR}$ for business units and then aggregating up to the corporate level.

One problem with any approach relying on firm-specific data for generating a probability distribution is the dependence on the relevance of the historical data used to estimate the variance-covariance matrix to the future that is to be forecasted. Stein et al (2001) apply what they call a comparables approach, which overcomes this problem of data availability. Based on four company characteristics (size, profitability, riskiness of industry cash flows, and stock price volatility), they sort companies into pools of comparable companies. Using historical cash flow data for all companies in a pool, they create a cash flow distribution that they apply to the individual companies in the pool. The comparables approach overcomes reliability problems in the assessment of $\mathrm{CFaR}$ in that the derived cashflow distribution reflects the collective experience of many comparable firms under a variety of market conditions. On the other hand, it relies heavily on the representativeness of the pool of comparable companies. Moreover, the comparables approach does not provide any information whatsoever on risk exposure. For this reason, the comparables approach does not really lend itself to risk management purposes.

\section{Assessing exposure to non-value-adding risk}

To the extent that non-value-adding risks are included as building blocks in the cash flow calculation, the pro forma approach provides information needed for managing risk exposures. The resulting risk exposures are alluring in that they are causally linked to cash flow. There are two dominating approaches to assessing corporate risk exposure: calculating exposure analytically and estimating it statistically. The analytical approach consists of specifying a causal mathematical model of corporate performance, for example, cash flow, as a function of macroeconomic and market risk and then calculating the effect of unexpected changes in the risk factors on performance. Well-known approaches to analytical exposure assessment are transaction exposure for exchange and commodity-price risk and maturity gap 
and duration for interest-rate risk. This is the approach to assessing risk exposure relied upon in the pro forma approach. Statistical exposure assessment instead consists of establishing a statistical link between cash flow and macroeconomic and market risks using regression analysis. Here, the linear regression coefficients measure risk exposure.

The pro forma approach's reliance on analytical exposure is useful if management has confidence in its mathematical models for risk exposure. In reality, risks operate on cash flow in many ways, few of which lend themselves to mathematical specification, and such risks often have interdependent effects that can either accentuate or offset each other. Reliance on analytical exposure appears to be contradicted by one of the main conclusions coming out of more than 30 years of research into how and why firms are exposed to macroeconomic and market risks, namely that corporate risk exposures tend to be so complex and multi-faceted as to defy any attempt at analytical modeling in a pro forma statement (see Bartram, 2000, for a review of the literature on corporate risk exposure). Take the case of exchange rate risk. The pro forma approach will typically only capture the direct impact of exchange rate changes on the value of foreign-currency denominated accounts payable and receivable. There is more to exchange-risk exposure, however. Changes in sales prices would, depending on price and cross-price elasticities, influence sales volumes. Real exchange-rate changes could result in shifts in competitiveness, which would spill over onto changes in demand.

Even when bottom-up modeling attempts to reflect such competitive and demand exposures by introducing more complex relationships between the exchange rate and cash flow, such modeling has a tendency to ignore the simultaneous impact of exchange rates and the effects of other, correlated macroeconomic and market variables such as interest rates, inflation, and commodity prices. An exchange rate change could, for example, influence interest rates, which in turn would influence interest expenses and consumers' consumption expenditures. What's more, since macroeconomic price variables are determined in a generalequilibrium system that simultaneously adjusts to shocks in the economy, there is a tendency for macroeconomic variables to co-vary that will influence the degree to which a firm is exposed to macroeconomic risks. And this means that, from the firm's point of view, the effects of inflation, interest rates, and exchange rates on cash flows can be partly or wholly offsetting.

Because of these complex linkages and interactions, the exposures that can be meaningfully captured in the pro forma approach are generally only a small part of a firm's 
total exposure. Analytical exposure assessment rather lends itself to situations where exposures can reliably be assumed to be simple and straightforward. Capturing intricate exposures instead requires estimating exposure statistically. CFaR can be improved by extending the analysis of risk exposure to cover interdependencies among different macroeconomic and market variables and the various channels through which such variables affect corporate cash flows (see, in particular, Oxelheim and Wihlborg, 1987, 1997, and 2008). The first step in the exposure assessment is a fundamental analysis of the company's exposures to changes in the macro economy. This is achieved by mapping the currency compositions of the company's sales, production costs, and input purchases, its positions on the factor and output markets and bargaining power relative to suppliers and customers, and the sensitivities of sales volumes to price, cross-price, interest rate, and real income changes. This analysis should also be undertaken on the firm's competitors so that the likely impact of changes in macroeconomic variables on competitiveness can be estimated.

The output of the fundamental analysis is a list of possibly important macroeconomic and market risks. They are then included as explanatory variables in a multivariate regression on corporate cash flow:

$$
X_{t}^{D C}-E_{t-1}\left[X_{t}^{D C}\right]=\beta_{0}+\sum_{i=1}^{n} \beta_{i}\left(F_{i t}-E_{t-1}\left[F_{i t}\right]\right)+\varepsilon_{t}
$$

where $X_{t}^{D C}$ is the cash flow in DC in period $t, F_{i t}, i=1 \ldots n$, represent explanatory variables, and $\varepsilon_{t}$ is an error term. As risk derives from unexpected deviations from forecasts, $\mathrm{E}[\mathrm{]}$ are included to capture forecasted developments in each period. The list of explanatory variables should include all non-value-adding risks identified in the fundamental analysis. We stress macroeconomic and market risks, such as exchange and interest rates, inflation, and commodity prices, for two reasons. Firstly, these are risks where few companies hold a comparative advantage due to the exogeneity of macroeconomic and financial-market developments to corporate performance and the lack of expertise in predicting macroeconomic and financial-market developments in most companies. It is important to point out that to the extent the firm is expected to be exposed to other non-value-adding risks that are not independent of macroeconomic and financial-market developments, these should be included in the list of explanatory variables in the exposure model. 
The coefficients produced by such a regression model provide measures of exposure that can then be put to three uses: (1) to determine the size of hedge contracts that will reduce or eliminate the company's exposure; (2) to adjust historical cash flow to filter out the impact of macroeconomic and market risks; and (3) to provide the basis for a $\mathrm{CFaR}$ calculation.

\section{Assessing exposure-based CFaR}

The exposure model decomposes total cash flow variability into fluctuations due to non-value-adding macroeconomic risk and fluctuations independent of such changes. We propose that if the exposure model is correctly specified, the residual term, $\varepsilon_{t}$, will capture the impact of value-adding risk on cash flow. The relative importance of the macroeconomic exposure is indicated by the coefficient of determination $\left(R^{2}\right)$ of the exposure model, while the relative importance of value-adding risk is given by $1-R^{2}$.

A conditional cash flow distribution is derived either by assuming normally distributed variables or through random sampling from a variance-covariance matrix for the explanatory variables in the exposure model. Assuming normally distributed data, it is straightforward to calculate cash flow risk conditional on the explanatory variables and CFaR. If using random sampling, sampled values are inserted into the exposure model to generate cash flow conditional on macroeconomic and market variables. To get an estimate of total cash flow, we must complement the conditional cash flow distribution with a distribution of the error term. If the error term is well behaved, it has by definition no correlation with any of the explanatory variables or its own past values, and we can simply draw a value from a normal distribution $\left(\mathrm{N} \sim\left[0, \sigma^{2}\right]\right)$ and add that value to the conditional distribution.

To summarize, calculating exposure-based CFAR consists of the following steps:

1. Fundamental analysis. Identify non-value-adding macroeconomic and market variables expected to be of importance to corporate performance by investigating the firm's operations, cost and revenue structures, and its macroeconomic and competitive environment.

2. Forecasting. Acquire or generate forecasts of the identified macroeconomic and market variables. 
3. Assessment of exposure. Estimate the exposure model. This is a process where knowledge of corporate fundamentals and statistics interact to derive a model that has both a plausible economic theory behind it and good statistical properties (high explanatory value, statistical significance, and well-behaved error terms).

4. Sampling. Deriving a cash flow distribution can be done numerically by assuming that all risk factors are normally distributed, simulated by randomly picking observations from the variance/covariance matrix, or simulated using historical simulation, where the historical time-series data is resampled. It is important to remember including the error term $\varepsilon$.

5. Generating cash-flow distributions. Sampled data is inserted into the exposure model to calculate both cash flow conditional on the explanatory variables and cash flow independent of macroeconomic and market risks.

6. Calculating CFaR. Finally, combine the two cash-flow distributions into one distribution for total cash flow, determine the targeted confidence level, and calculate CFaR.

\section{Applying exposure-based CFaR to the case of Norsk Hydro}

For expositional purposes we draw upon Andrén, Jankensgård, and Oxelheim (2005) in demonstrating the application of exposure-based CFaR to an actual company, Norsk Hydro, a Norwegian aluminum manufacturer headquartered in Oslo. The case covers an earlier period in the history of Norsk Hydro, 1996 to 2003. Back then, Norsk Hydro was an industrial conglomerate with activities in oil, aluminum, and fertilizer production. The company has since divested its fertilizer and oil businesses and is today a pure-play aluminum manufacturer. Our analysis uses as the target cash flow variable EBITDA as a proxy for operating cash flow. EBITDA effectively excludes the effect of financing and hedging decisions. Unfortunately, the cash-flow numbers available to us are not filtered from all hedging activities. For example, Hydro reports contracts locking in commodity prices as part of operating income. We follow the six-step process just outlined, starting with an investigation of the potential exposure to macroeconomic and market risks of each of Hydro's main businesses. 
Hydro's strategy throughout the 1990s and early 200s was to focus on three main business areas: Oil, Aluminum, and Fertilizers (Agri). In 2002, it acquired the German aluminum maker VAW, establishing itself as one of the world's three largest integrated players in the aluminum market. In 2003, the company's total operating revenues were NOK 172 billion (or roughly $\$ 25$ billion). Of that total, the oil \& gas division (HOE, or Hydro Oil \& Energy) accounted for $35 \%$, Hydro Aluminum (HAL) for $40 \%$, the fertilizer business Hydro Agri (HA) for 22\%, and other activities for the remaining 3\%. In 2003, Hydro's board decided to divest the fertilizer division (HA), and the divestment took place in early 2004 . We focus on the period prior to the divestment of HA and thus include the division in our case study.

\section{Step 1: Fundamental analysis}

In the analysis that follows, we consider four major sources of macroeconomic and market risk faced by Hydro in 2003: commodity prices, exchange rates, inflation rates, and interest rates.

Channels of exposure to commodity-price risk. A large part of HOE's commercial output was exposed to changes in the price of oil. Hydro's production of oil and oil equivalents in 2003 amounted to 530,000 barrels of oil per day. The downstream portion of HOE's oil activities was small relative to that of many of its competitors, and Hydro's oil division had remained essentially an exploration and production company. Gas production was also growing in importance, but as of early 2004 there was only a minor exposure to the spot price of gas as HOE's portfolio of gas contracts consisted mainly of long-term contracts written with reference to the oil price.

In 2003, HAL produced a total of 1.5 million tons of aluminum. The company's exposure to the aluminum price was somewhat mitigated by having some of the costs of inputs linked to it. Aluminum is a standardized product, where the global nature of the market makes each player basically a price taker. HAL also had a large downstream sector that refined and then sold aluminum to the car and aviation industries, among others. HAL competed mainly with two other integrated aluminum producers, Alcoa in the U.S. and Alcan in Canada. Because aluminum production is an energy-intensive process, HAL had a large exposure to energy prices on the cost side, but its exposure to the spot price of electricity was managed through the use of long-term purchase contracts. 
The market for fertilizers has a huge number of players, each with only a small slice of total market share. HA, although the world leader, had a global share of no more than $6 \%$. In Western Europe, HA had a market share of $25 \%$ in nitrate fertilizers, for which Urea and Can serve as reference prices. There were numerous fertilizers and related products in HA's product portfolio and the business operated in about 50 countries, and sold to over 100 countries worldwide, implying a very complex market setting. Ultimately, though, all these products were expected to respond to the same factors: the overall development in the demand for grain and the expected profitability of the farming industry. On the cost side, manufacturing Urea and Can requires ammonia $\left(\mathrm{NH}_{3}\right)$ as a primary input, and $\mathrm{NH}_{3}$ production in turn requires significant amounts of natural gas. An increase in the price of gas (which is highly correlated with Light Sulphate Fuel Oil, an oil derivative) tends to be passed through to $\mathrm{NH}_{3}$, which in turn is passed through to Urea and Can. The degrees of pass-through, which depend on a lot of factors and varies over time, determine the extent of the correlation between these variables and therefore also HA's overall exposure to fertilizers and oil.

To summarize, we identify five main sources of commodity price exposure facing Hydro in 2003: the prices of oil, aluminum, Urea, Can, and $\mathrm{NH}_{3}$.

Channels of exposure to exchange rate risk. The oil price is a world commodity with the reference price set in USD dollars, while HOE's cost base was heavily concentrated in Norway. The non-Norwegian share of oil production was on the rise, but accounted for only $11 \%$ of total production. The strength of the NOK to the USD should thus be a positive determinant of Hydro's performance relative to the industry.

The world aluminum price is also set in USD. HAL's aluminum production was sold mainly in Europe and invoiced in EUR. HAL's upstream production had a large portion of its cost base in Norway and EUR, making the NOK/EUR rate important. Downstream production and sales were largely located to the European market, but with some production in Norway; and thus while HAL and its main competitors competed in the same product markets, they had their main cost bases in different currencies. Thus, to the extent the NOK weakens against USD and CAD, this would tend to benefit HAL relative to its competitors, particularly in downstream operations.

Roughly speaking, the reference price for Urea is set in USD, whereas Can has its reference price in EUR, but the USD is considered to be the functional currency for both 
commodities. HA's sales were mainly invoiced in USD and EUR, but parts were invoiced in local currencies. This created a situation in which there was a short-term transaction exposure to a number of local currencies, but where the underlying exposure should be to the USD. Competitive effects of exchange rates are known to exist. For example, changes in the USD/EUR rate alter the relative attractiveness of Urea and Can, two fertilizer products that are of differing quality but essentially substitutes. As for currency exposures on the cost side, HA sales were highly geographically diversified, but the major production centers were located in Norway (NOK) and the Netherlands (EUR), making NOK/EUR and NOK/USD potentially important currencies.

To summarize, we identify three sources of exchange risk exposure: NOK/USD, NOK/EUR, and NOK/CAD.

Channels of exposure to inflation risk. The importance of exchange rate risk to competitiveness is also determined by inflation differentials. If exchange rate changes are completely offset by inflation differentials, exchange rates will not influence competitiveness. Companies with exposure to relatively higher inflation rates in their cost base may find it harder to compete on price and either lose market share or have lower margins. HAL had the conditions for this type of exposure since the three major players in the aluminum industry had the main part of their cost bases in different currencies. HOE could also be exposed to relative inflation rates, given the effect of the local cost base and standardized output in negating any cost pass-through. By contrast, HA was more diversified and thus presumably less sensitive to inflation-induced competitive exposures.

More generally, inflation can influence performance negatively if costs tend to rise faster with inflation than revenues. All of Hydro's product prices were pro-cyclical and hence could be assumed to reflect inflation rates in the economy. But whether the company's cost bases generally had higher inflation rates is hard to determine a priori and is largely an empirical matter.

To summarize, we identify four sources of exposure to inflation risk: inflation in Norway, the EMU, the US, and Canada.

Channels of exposure to interest rate risk. Interest rates can have an effect on operating cash flow to the extent demand in an industry is sensitive to the cost of capital. This clearly applies to the aluminum industry, where buyers of refined aluminum products are often in 
very capital-intense industries, and for farmers using Agri's fertilizers, as agriculture is also capital intensive. Accordingly, long-term European and U.S. interest rates could be expected to be important determinants of HAL's and HA's interest rate risk exposures.

One might also empirically observe a cash flow sensitivity to the interest rate to the extent that it proxies for the business cycle and the development in aggregate demand. HAL, in particular, was known to be cyclical. Aluminum prices are pro-cyclical (the aluminum price is highly correlated with industrial production), making it an empirical issue whether interest rates or aluminum prices capture this cyclicality. HOE was also partly cyclical but, again, it is uncertain whether interest rates or oil prices provide the best proxy for this cyclicality and risk.

A third effect of interest rates on operating cash flow could arise if our definition of EBITDA was changed to include the interest income and expenses from current assets. Hydro does have an item called "financial expense on operating capital," which includes factoring costs, so the short-term reference interest rate could have a negative effect on EBITDA. However, the size of this item in 2003, NOK 35 million, indicates that the size of this exposure should be negligible.

To summarize, we identify three sources of interest rate exposure: Norwegian, European, and U.S. long-term interest rates.

\section{Step 2: Forecasting}

Risk derives from unexpected changes in macroeconomic and market variables, and the estimation of exposures to risk thus requires forecasts of such variables. It is important to point out that we focus on expositional clarity rather than getting absorbed by statistical excesses. Since our focus is on $\mathrm{CFaR}$ rather than the intricacies of estimating exposure and given our use of quarterly data, we assume that all variables included follow random walks, which means that all changes are unexpected. Since we are working primarily with market risks, the use of forward rates as market forecasts would be a reasonable alternative.

\section{Step 3: Assessment of exposure}

As discussed earlier, the target variable used when assessing exposure should be consistent with the objective of the firm and its evaluation system. We use EBITDA as a proxy for operating cash flow. The choice of target variable is determined by the objective of 
the risk management activities. If the purpose is to reduce the probability of financial distress (Smith and Stulz, 1985) or stabilizing the supply of internal cash flow (Froot et al, 1993) it would be preferable to use a more encompassing definition of cash flow also reflecting taxes and required investments in working capital and long-term operating assets and liabilities (see Koller, Goedhart, and Wessels, 2005 for an overview of various components of cash flow). The cash flow data we use are quarterly EBITDA in NOK for each of the three main businesses (HOE, HAL, and HA) as well as the entire company (HG) starting with the first quarter of 1996 and running through the end of 2003. Our data on commodity prices, exchange, interest, and inflation rates are quarterly averages over the same period collected from the EcoWin Economic and Financial database. In defining the key relationships in our model, we chose Brent Crude as the USD reference price for oil produced in the North Sea. The Aluminum price is the USD spot price as quoted on the London Metal Exchange. Urea and Can are fertilizer prices in USD and EUR, and $\mathrm{NH}_{3}$ (in USD) is the price of ammonia. The long-term interest rates are the yields to maturity on 10-year German, Norwegian, and U.S. government bonds. Inflation rates are based on CPI All Items in the U.S., the EMU, Norway (NO), and Canada (CA). Quarterly dummies are included to control for any seasonal cash flow patterns.

It is important that the analysis be performed on structurally stable data. If the company or its environment has experienced too many or large fundamental changes, it will be more difficult to extract the information we are looking for from the data set. Although some significant restructurings have been carried out in this period, HG's overall business model has been fairly stable.

Exposure can be estimated using data expressed in levels, first differences, or percentage changes. From an informational point of view, it should be noted that information in one dimension can easily be expressed in terms of another, so in that sense the choice is irrelevant. Instead the statistical properties of the time series should guide the decision. As a general principle, time series should be stationary. Further guidance should come from an analysis of the model's error terms. To induce stationarity, regressions were run using data in first differences on non-logged data. Error terms have been subjected to the Breusch-Godfrey test for serial correlation and the Jarque-Bera test for normality.

Specifying an acceptable exposure model is a combination of art and science. Our preferred exposure models include variables with a strong basis in economic theory that are 
Table 1 Estimated exposure models for Norsk Hydro and its three divisions (1996:I to 2003:IV). Coefficients show average cash flow changes in Mn NOK from one-unit increases in the independent variables.

\begin{tabular}{|c|c|c|c|c|}
\hline & $H O E$ & $H A L$ & $H A$ & $H G$ \\
\hline Intercept & $516(0.05)$ & $-131(0.32)$ & $3(0.97)$ & $76(0.82)$ \\
\hline Brent Crude & $219(0.00)$ & & $-26(0.10)$ & $135(0.05)$ \\
\hline Aluminum & & $3(0.00)$ & & $4(0.06)$ \\
\hline $\mathrm{NH}_{3}$ & & & $3(0.08)$ & \\
\hline Urea & & & $10(0.01)$ & $16(0.01)$ \\
\hline \multicolumn{5}{|l|}{ Can } \\
\hline NOK/USD & $676(0.13)$ & $-392(0.09)$ & $240(0.11)$ & \\
\hline NOK/EUR & & $702(0.06)$ & & \\
\hline \multicolumn{5}{|l|}{ NOK/CAD } \\
\hline \multicolumn{5}{|l|}{ Gvt 10y US } \\
\hline \multicolumn{5}{|l|}{ Gvt 10y Norway } \\
\hline \multicolumn{5}{|l|}{ Gvt 10 Germany } \\
\hline \multicolumn{5}{|l|}{ Inflation US } \\
\hline \multicolumn{5}{|l|}{ Inflation NO } \\
\hline \multicolumn{5}{|l|}{ Inflation EMU } \\
\hline \multicolumn{5}{|l|}{ Inflation CA } \\
\hline Q1 & $51(0.89)$ & $496(0.02)$ & $574(0.00)$ & $1,306(0.01)$ \\
\hline Q2 & $-1,006(0.01)$ & $294(0.13)$ & $-87(0.47)$ & $-385(0.42)$ \\
\hline Q3 & $483(0.19)$ & $-39(0.83)$ & $-367(0.01)$ & $-342(0.49)$ \\
\hline $\mathrm{R}^{2}$ & 0.56 & 0.52 & 0.82 & 0.69 \\
\hline $\mathrm{SE}$ of regression & 700 & 359 & 225 & 878 \\
\hline BG statistic & 1.14 & 0.70 & 2.95 & 1.49 \\
\hline JB statistic & 9.88 & 0.18 & 1.97 & 0.64 \\
\hline
\end{tabular}

supported by empirical evidence. In other words, to gain acceptance from top management, a risk management model must have not only statistical backing, but a clear and compelling logic as to how we would expect the main variables to affect the company's cash flow; in short, the model must make statistical, economic, and managerial sense.

The results of the exposure assessments are presented in Table 1. Our HOE exposure model indicates a Brent exposure of NOK 219 million. This means that, over the eight-year period we examine, a one dollar increase in the oil price was accompanied, on average, by an increase in HOE's cash flow of NOK 219 million. This is also our forecast of the relationship 
between future oil price changes and cash flow. It is important to note that the coefficients show the marginal exposures to the risk factors, assuming that all other variables in the model are held constant. That is, the 219 million oil price exposure is estimated on the assumption that the NOK/USD rate remains constant. As expected, cash flow increased both when the oil price increases and when NOK depreciates against the USD.

The results in Table 1 also confirm our expectation that HAL's cash flow increased with increases in the EUR price of aluminum and with depreciations of the NOK against the EUR. Somewhat surprisingly, however, our results suggest that the aluminum division's cash flows declined in response to depreciations of the NOK/USD. Thus it appears that HAL, contrary to both our and management's own assumptions, does not have an effective long position in USD. ${ }^{1}$ Moreover, our finding of a short position in USD is stable across model specifications and independent of the sample period used (results not reported). The main reason for believing that HAL had a long position in USD is the fact that aluminum is traded in USD. But our results, together with further thought on this issue, have led us to recognize the possibility that if the aluminum market is perfectly competitive, all changes in USD/EUR would be passed through to EUR (Hydro's invoice currency) and a strengthening USD would lead to increasing EUR sales prices. This price impact would be captured by the NOK/EUR rate, since Hydro's direct transaction exposure is to EUR. However, price increases would reduce demand, which would generate a negative marginal exposure, once NOK/EUR is controlled for, which would be captured by the NOK/USD rate. This negative exposure is countered by a competitive exposure to NOK/USD in the downstream operations. It seems like the demand effect dominates. Moreover, HAL's short position in USD may actually result at least in part from management's belief - and the actions based on that belief - that the division was long USD.

As we expected, HA's cash flow was affected negatively by oil price increases, but positively by increases in the prices of $\mathrm{NH}_{3}$ and Urea and depreciations of the NOK/USD. Finally, the entire company (HG) appears to have had long positions in oil, aluminum, and $\mathrm{NH}_{3}$.

\footnotetext{
${ }^{1}$ Hydro's 2003 annual report (page 85) states, "Normally, Hydro's operating income will increase when the US dollar appreciates against European currencies and decline when the value of the US dollar falls. To reduce the long-term effects of fluctuations in the US dollar exchange rates, Hydro has issued most of its debt in US dollars." Hydro also estimates the impact on pre-tax income of a 1 NOK/USD increase to be NOK $875 \mathrm{Mn}$.
} 
One notable finding is that the coefficient on the aluminum price is slightly larger for the entire company $(\mathrm{HG}=\mathrm{NOK} 4 \mathrm{Mn})$ than for the aluminium business $(\mathrm{HAL}=\mathrm{NOK} 3 \mathrm{Mn})$. This result suggests that the price of aluminum functions partly as a proxy for the business cycle and captures cyclical effects on other cash flows. The same is true of the coefficient on $\mathrm{NH}_{3}$ in the $\mathrm{HG}$ model relative to its coefficient in the HA model. In the HG model, which excludes Urea, $\mathrm{NH}_{3}$ captures the exposure of this variable and that of the other fertilizer products.

Steps 4-6: Sampling, generating cash-flow distributions, and calculating CFaR

To calculate exposure-based $\mathrm{CFaR}$, we need an estimate of the variance-covariance matrix for the risk factors. We use the same data set used for estimating the exposure models - that is, quarterly averages from 1996-2003 collected from the EcoWin database - while continuing to assume that the risk factors follow random walks without trend. Standard deviations and correlations of quarterly first differences are shown in Table 2.

Table 2 Standard deviations and correlations of the independent variables (quarterly changes 1996:I-2003:IV)

\begin{tabular}{|c|c|c|c|c|c|c|}
\hline & \multirow[b]{2}{*}{$\begin{array}{l}\text { Standard } \\
\text { deviation }\end{array}$} & \multicolumn{5}{|c|}{ Correlations } \\
\hline & & Aluminum & $\mathrm{NH}_{3}$ & Urea & $\begin{array}{l}\text { NOK/ } \\
U S D\end{array}$ & $\begin{array}{l}\text { NOK/ } \\
\text { EUR }\end{array}$ \\
\hline Brent crude & 2.9 & 0.37 & 0.23 & 0.21 & -0.13 & -0.39 \\
\hline Aluminum & 86 & & -0.08 & 0.01 & 0.47 & -0.35 \\
\hline $\mathrm{NH}_{3}$ & 29.6 & & & 0.48 & -0.30 & 0.11 \\
\hline Urea & 14.6 & & & & -0.31 & 0.06 \\
\hline NOK/USD & 0.31 & & & & & 0.17 \\
\hline NOK/EUR & 0.19 & & & & & \\
\hline
\end{tabular}

Using the variance-covariance matrix summarized in Table 2 and random sampling, we programmed a simulation software called @ Risk to run 10,000 scenarios of the variables 
in the forecasting system, including explanatory variables, quarterly dummies, and error terms. Generated forecasts for the explanatory variables were then inserted into the relevant exposure model from Table 1. By so doing, we ended up with a distribution of expected cash flow that reflects not just the cash flow sensitivities to each of the individual risk factors, but also the expected variances and covariances of those risks. The resulting cash-flow distributions in turn enabled us to estimate the CFaRs for the next quarter (Q1 2004) for each of the three business areas. These are summarized in Table 3 and depicted graphically for the company as a whole in Figure 1.

Table 3 Exposure-based CFaR estimates for 2004:I (Mn NOK)

$\begin{array}{llll}\text { Expected } & 5^{\text {th }} \text { percentile } & \text { CFaR } & \text { CFaR in percent } \\ \text { Cash Flow } & \text { Cash Flow } & & \end{array}$
(A)
(B)
$(C=A-B)$
$(D=C / A)$

\begin{tabular}{lcccc}
\hline HOE & 9,706 & 8,105 & 1,601 & $16.5 \%$ \\
HAL & 2,167 & 1,498 & 669 & $30.9 \%$ \\
HA & 2,061 & 1,572 & 489 & $23.7 \%$ \\
\hline HG & 13,814 & 11,811 & 2,002 & $14.6 \%$
\end{tabular}

Figure 1 Simulated Distribution for HG's cash flow, 2004:1

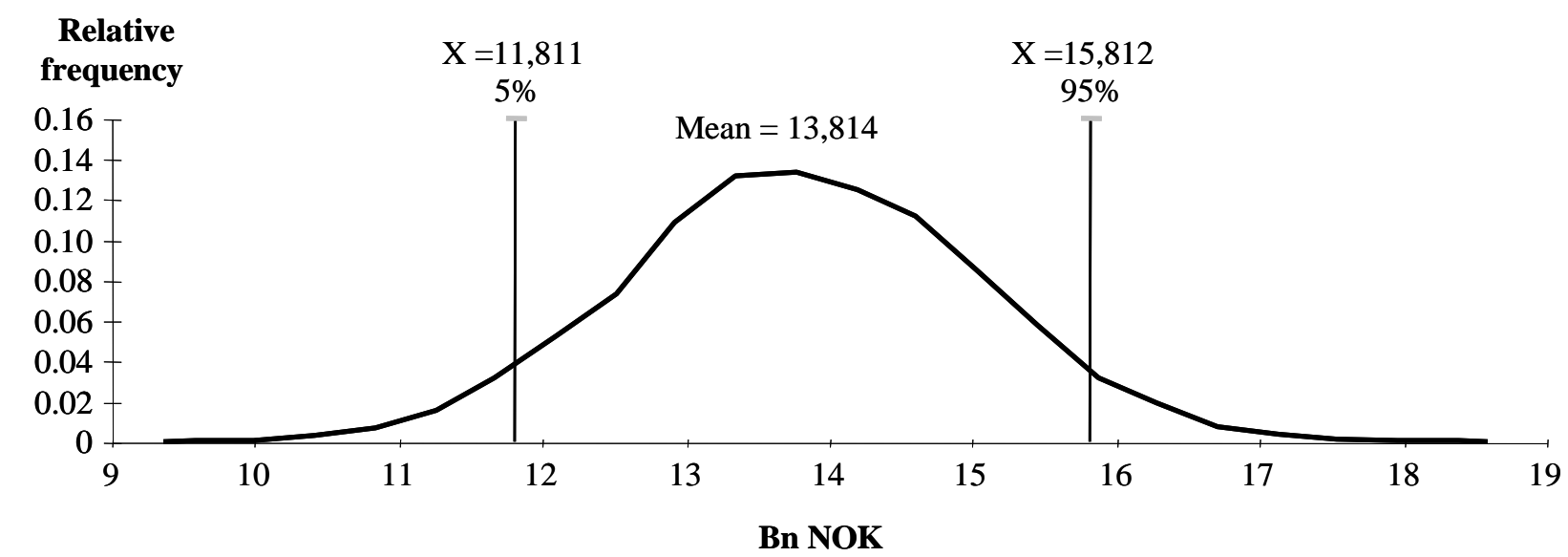


How do we interpret the information in Table 3? As an example, given our selected confidence level of $95 \%$, we interpret the CFaR estimate for $\mathrm{HG}$ as follows: we are $95 \%$ certain that the company's cash flow (EBITDA) will not fall short of the expected amount of NOK 13,814 million by more than NOK 2,002 million. In other words, we expect cash flow to fall below NOK 11,812 million $(13,814-2,002)$ in only one quarter out of 20 . Table 3 also shows that of the three main businesses, HAL's cash flow is associated with the largest risk $(31 \%)$.

\section{Analyzing the corporate risk portfolio}

Exposure-based $\mathrm{CFaR}$ opens up rich possibilities for decomposing the $\mathrm{CFaR}$ estimate into individual risk exposures, thereby providing insights into the cash flow dynamics of the company and the key drivers of risk. In particular, the method allows for a clearer view of the portfolio aspects of corporate risk.

Portfolio considerations exist on three levels. First, there may be offsetting exposures, or what amount to natural hedges, in Hydro's portfolio of exposures. For example, HOE had a long position in Brent, as indicated by the 219 million exposure coefficient (see exposure models in Table 1), whereas HA had an offsetting short position of NOK -26 million. While the NOK/USD exchange rate is significant for each of the three business areas when viewed separately, there is no significant exposure to the company as a whole (HG) ( $p$-value $=0.25$ if it were included in the model). Thus, the long positions of HOE and HA in USD appear to be cancelled out by HAL's short position.

Second, the error terms in the regressions, which reflect cash flow changes independent of the macroeconomic and market risk factors, could be correlated across business areas. A correlation between the error terms would indicate that there is a tendency for macro-independent changes to be systematic across business areas. An analysis of the error terms from the models in Table 1 indicates that the correlations are generally insignificant, which suggests that the macro-independent changes in cash flows are diversified in the HG portfolio.

Third, there could be a portfolio effect from exposures to correlated risk factors. A high correlation between two risk factors will have an impact on estimated $\mathrm{CFaR}$, and the sign 
of the exposure coefficients determines whether the overall net impact is positive or negative. If two risk factors are positively correlated, but the firm is negatively exposed to one and positively to the other, there is a dampening effect on cash flow risk. Looking at Table 2, we see that the correlations among risk factors are generally low, implying that there is a clear diversification effect. But some of Hydro's product prices do appear somewhat correlated. For example, the correlation coefficient between the prices of the company's two main commodities, oil and aluminum, is 0.39 . Of all the correlations, this one is likely to have the largest bearing on overall risk. Furthermore, Urea and $\mathrm{NH}_{3}$ have a correlation of 0.48 .

Another insight that comes from taking a portfolio view of risk is that, in some cases, not all product prices need be included in the exposure models. In the HG model, for example, the inclusion of $\mathrm{NH}_{3}$ alone seems sufficient to capture the entire commodity price exposure of the fertilizer business. In such a case, managing exposure to a single price that, because of high correlations, represents exposures to a whole category of risks could mean major savings in terms of transaction costs.

All in all, then, the effects of less-than-perfect correlations and natural hedges add up to lower risk at the Hydro group level as compared to the sum of the risks in the three main business areas. As a measure of this diversification benefit, the $\mathrm{CFaR}$ for Hydro Group reported in Table 3 is NOK 2,002 million, considerably lower than the sum of the CFaRs for the three business areas (NOK 2,759Mn). The difference of NOK 757 million can be attributed to the natural hedges provided by the less-than-perfect correlations between the risk factors and the error terms.

\section{Exposure-based CFaR and hedging}

Another benefit of exposure-based CFaR is its ability to inform hedging decisions. Using the CFaR methodology, management can readily assess the impact on cash flow variability of different hedging strategies. Indeed, much of the information necessary for deciding the size of the hedge position is contained in the coefficients in the exposure model. For example, in the HA model, the indicated exposure to NOK/USD is 240 million for each NOK depreciation to the dollar (as shown in Table 1). This means that if management wishes to neutralize its exposure to this exchange rate for the next quarter, it would sell forward exactly this number of dollars. The forward position would then have the same exposure as 
HA's cash flow, but with opposite sign, and they would cancel out, leaving HA's cash flow unexposed. For example, if the NOK were to depreciate by 0.10 NOK to the dollar, cash flow would increase by 24 million. But the forward position would fall by the same amount, neutralizing the effect on Hydro's cash flow.

The effectiveness of such partial hedges in terms of reducing cash flow risk depends on three factors: (1) the size of the exposure; (2) the volatility of the risk factor being hedged; and (3) the correlation between the risk factor being hedged and other risk factors in the model. The effects of 1 and 2 are likely to be the most important ones. Generally speaking, the combined effect of exposure and volatility will determine a risk factor's contribution to cash flow volatility. We have compared the effects of hedging $100 \%$ of the exposure for all variables in the Hydro Group model (in reality, there is no forward market for $\mathrm{NH}_{3}$, but we assume the risk can be hedged). The base case CFaR is the number reported for $\mathrm{HG}$ in Table 3. As indicated by Table 4, hedging the exposure to Brent is the most effective way of reducing risk (provided this is management's goal). While $\mathrm{NH}_{3}$ has a higher volatility than Brent, Hydro has a much larger exposure to Brent, which is the dominating effect in this case. Exposure to the aluminum price is also relatively large, but the effect of an aluminum hedge on risk is limited by the relative stability of the aluminum price.

Table 4 Hydro Group's CFaR estimates under different hedging strategies

\begin{tabular}{llll}
\hline & $\begin{array}{l}\text { Base case CFaR } \\
\text { (no hedge })\end{array}$ & $\begin{array}{l}\text { Hedged CFaR (100\% } \\
\text { hedge of each risk } \\
\text { factor })\end{array}$ & Risk reduction in \% \\
\hline Brent crude & 2,002 & 1,727 & $13.7 \%$ \\
Aluminum & 2,002 & 1,829 & $8.6 \%$ \\
$\mathrm{NH}_{3}$ & 2,002 & 1,777 & $11.2 \%$ \\
\hline
\end{tabular}

\section{Separating between value-adding and non-value-adding risks}

A further decomposition of exposures can be made by distinguishing between the effects of macroeconomic risk and cash-flow changes independent of macroeconomics. To the extent the exposure models capture the impact of non-value-adding risks, the independent 
component will capture the influence of value-adding risks. For Hydro Group, macroeconomic and market risks account for about $69 \%$ of the variability in cash flow as measured by $R^{2}$. The CFaR conditional on these macroeconomic and market risk factors is estimated to be NOK 1,385 million, as compared to the CFaR estimated from macroindependent changes of NOK 1,444 million (to see how these respective numbers are estimated, see steps 4 and 5 in the six-step process described earlier). The two risk components are not additive since the error term is defined to be the cash flow volatility independent of macroeconomic and market risk (additivity would only come about in the case of perfect correlation.) We also observe that while over two thirds of cash flow volatility is explained by the exposure model, this doesn't necessarily mean that the conditional CFaR is higher than the $\mathrm{CFaR}$ due to value-adding risks. This will depend on the degree of volatility and correlation among the explanatory variables in the model relative to the volatility of error terms.

As stated earlier, we argue that an exclusive focus on either conditional CFaR or total $\mathrm{CFaR}$ is likely to be a mistake. Only by examining both of these distributions can corporate managers get a meaningful indicator of uncertainty about future cash flow. An exclusive focus on the distribution of macro-independent changes could lead to a minimum-variance strategy, one in which all hedgeable exposures are reduced to zero. By hedging all its macroeconomic and market risk, Hydro could reduce the CFaR to NOK 1,444 million (the $\mathrm{CFaR}$ from macro-independent changes alone).

\section{Concluding remarks on the exposure based CFaR for value adding risk management}

Cash Flow at Risk is the cash flow equivalent of Value at Risk, which is widely used as the basis for the risk management systems within financial institutions. CFaR promises the same potential among industrial companies for much the same reasons as VaR has succeeded with financial firms: it sums up all the company's risk exposures into a single number that can be used to guide corporate risk management and performance management.

Competitive advantage derives from having the ability to identify and exploit inefficiencies in markets for real production factors (Barney, 1986). A gold miner owning a mine with richer ores than competitors would, if the access to the unique production factor is managed correctly, be able to generate residual incomes in excess of the cost of capital. The same could 
be said for a consumer company with unique abilities in designing products or services that are perceived by cosumers as more attractive than competing offers. Executives and academics tend to frame argumentations on competitive advantage in terms of assets and capabilities and overlook that the argumentation could be applied to risk taking as well. The gold miner might have an advantage in bearing the risk of exploration or extraction, while the consumer company's comparative advantage in bearing risk may apply to human resource management or research and development. The gold miner may have no comparative advantage in bearing the risk of the price of gold, implying that the firm may be better off hedging the gold price risk. The consumer company may instead hold no advantage in manufacturing and may benefit from outsourcing its production to a firm specializing in manufacturing consumer products.

Why is the distinction between value-adding and non-value-adding risk relevant? Because there is a limit to corporate risk taking. Corporate stakeholders, not least owners and creditors, but also, for example, suppliers, customers, and employees may not accept unlimited risk taking. This is apparent in the banking industry, where the Basel II framework specifies minimum capital requirements based on the bank's risk taking; the greater the risks taken by the bank, the greater the required equity cushion in the form of tier I and II capital. The same logic applies to non-banking business. All risk taking requires an equity cushion, either explicitly in the form of on-balance-sheet equity, or indirectly in the form of investment in risk prevention, owner guarantees, or by facing a greater credit risk premium on credit financing (Merton and Perold, 1993). Being exposed to non-value-adding risk will thereby limit the firm's ability to add exposure to value-adding risk. By reducing the exposure to nonvalue-adding risk, management may accordingly increase its investments in value-adding risks.

Our approach to $\mathrm{CFaR}$, which we call exposure-based $\mathrm{CFaR}$, provides the strategic $\mathrm{CFO}$ with a comprehensive framework for handling non-value adding risks. The framework involves the estimation of a set of exposure coefficients that provide information about how various macroeconomic and market variables are expected to influence the company's cash flow, and that also attempt to take account of interdependencies and correlations among such effects. The resulting exposure model gives the strategic CFO a set of exposure coefficients that is capable of explaining the variability in cash flow as a function of various risks; and for this reason, it can also be used to predict how a hedging contract or change in financial 
structure will affect the company's risk profile. At the same time, our framework also provides information about that part of the firm's cash flow variability that is not attributable to macroeconomic and market risks, but is necessary in calculating the firm's overall variability and $\mathrm{CFaR}$.

\section{References}

E.I. Altman, "Financial Ratios, Discriminant Analysis and the Prediction of Corporate Bankruptcy,” Journal of Finance Vol. 4, No. 4 (1968), pp. 589-609.

E.I. Altman and A. Saunders, "Credit Risk Measurement Developments Over the Last 20 Years," Journal of Banking and Finance Vol. 21, No. 11-12 (1998), pp. 1721-1742.

N. Andrén, H. Jankensgård, and L. Oxelheim, ”Exposure-Based Cash-Flow-at-Risk: An Alternative to VaR for Industrial Companies," Journal of Applied Corporate Finance Vol. 17, No. 3 (2005), pp. 76-86.

J.B. Barney, "Types of Competition and the Theory of Strategy: Toward an Integrative Framework", Academy of Management Review Vol. 11, No. 4 (1986), pp. 791 800.

S.M. Bartram, "Corporate Risk Management as a Lever for Shareholder Value Creation", Financial Markets, Institutions \& Instruments, Vol. 9, No. 5 (2000), pp. 279-324.

K. Borch, "The Theory of Risk," Journal of the Royal Statistical Society Vol. 29, No. 3 (1967), pp. 432-467

C. Culp, M. Miller, and A. Neves, "Value at Risk: Uses and Abuses," Journal of Applied Corporate Finance Vol. 10, No. 4 (1998), pp. 26-38.

K. Froot, D. Scharfstein, and J. Stein, "Risk Management: Coordinating Corporate Investment and Financing Policies,” Journal of Finance Vol. 48 (1993), pp. 1629-1658.

K. Froot, D. Scharfstein, and J. Stein, “A Framework for Risk Management,” Harvard Business review Vol. 72, No. 6 (1994), pp. 91-102. 
D. Kahneman and A. Tversky, "Prospect Theory: An Analysis of Decision Under Risk,” Econometrica Vol. 47, No. 2 (1979), pp. 263-291

T. Koller, M. Goedhart, and D. Wessels, Valuation. Measuring and Managing the Value of Companies (Chichester, UK: Wiley, 2005).

R. Libby and P.C. Fishburn, "Behavioral Models of Risk Taking in Business Decisions: A Survey and Evaluation,” Journal of Accounting Research Vol. 15, No. 2 (1977), pp. 272-292

D. Mayers and C.W. Smith Jr, “On the Corporate Demand for Insurance," Journal of Business Vol. 55, No. 2 (1982), pp. 281-296.

R.C. Merton, "You Have More Capital Than You Think," Harvard Business Review November Vol. 83, No. 11 (2005), pp. 84-94.

R.C. Merton and A. Perold, "Theory of Risk Capital in Financial Firms", Journal of Applied Corporate Finance Vol. 6, No 3(1993), pp. 16-32.

K. Miller and M. Leiblein, “Corporate Risk-Return Relations: Returns Variability versus Downside Risk," Academy of Management Journal Vol. 39, No. 1 (1996), pp. 91-122.

L. Oxelheim and C. Wihlborg, Macroeconomic Uncertainty. International Risks and Opportunities for the Corporation (Chichester, UK: Wiley, 1987).

L. Oxelheim and C. Wihlborg, Managing in a Turbulent World Economy: Corporate Performance and Risk Exposure (Chichester, UK: Wiley, 1997).

L. Oxelheim and C. Wihlborg, Corporate Decision-making with Macroeconomic Uncertainty (New York: Oxford University Press, 2008).

RiskMetrics, CorporateMetrics ${ }^{T M}$ Technical Document (New York: RiskMetrics Group, 1999).

C. Schrand and H. Unal, "Hedging and Coordinated Risk Management: Evidence from Thrift Conversions," Journal of Finance Vol. 53, No. 3 (1998), pp. 979-1013.

J. Scott, "The Probability of Bankruptcy. A Comparison of Empirical Predictions and Theoretical Models," Journal of Banking and Finance Vol. 5, No. 3 (1981), pp. 317-344 
C.W. Smith and R.M. Stulz, “The Determinants of Firms' Hedging Policies," Journal of Financial and Quantitative Analysis Vol. 20, No. 4 (1985), pp. 391-405.

J. Stein, S. Usher, D. LaGatutta, and J. Youngen, “A Comparables Approach to Measuring Cashflow-at-Risk for Non-Financial Firms", Journal of Applied Corporate Finance Vol. 13, No. 4 (2001), pp. 100-109.

R.M. Stulz, "Rethinking Risk Management," Journal of Applied Corporate Finance Vol. 9, No. 3 (1996), pp. 8-24. 